(2) Open Access Full Text Article

REVIEW

\title{
Analog insulin detemir for patients with type I and type 2 diabetes: a review
}

This article was published in the following Dove Press journal:

Diabetes, Metabolic Syndrome and Obesity:Targets and Therapy

13 May 2009

Number of times this article has been viewed

\author{
Gregory E Peterson \\ Department of Internal Medicine, \\ Des Moines University, USA
}

Correspondence: Gregory E Peterson

Diagnostic and Critical Care Medicine,

4II Laurel Street-Suite 3275,

Des Moines, IA 503I4, USA

Email gepeterson@dccmiowa.com
Objective: To review insulin detemir for clinical use to better manage patients with type 1 and type 2 diabetes.

Methods: A MEDLINE search, in English, from June 30, 2006 to December 1, 2008, using the terms "insulin analogs," "insulin detemir" and "long-acting insulin analog."

Results: Insulin detemir improves glycemic control, based on $\mathrm{HbA}_{1 \mathrm{C}}$ reduction and fasting glucose levels, without increasing the risk of hypoglycemia and weight gain. Insulin detemir has lower glycemic variability, with less intra-subject variability in blood glucose levels in patients with type 1 and type 2 diabetes, without increasing the risk of hypoglycemia. When added to oral anti-diabetes agents (OADs) in type 2 diabetes, insulin detemir demonstrates superiority to other basal insulin options.

Conclusion: Insulin detemir appears to provide better glycemic control with a lower risk of hypoglycemia and less weight gain in the treatment of patients with type 1 and type 2 diabetes.

Keywords: type 1 diabetes, type 2 diabetes, insulin analogs, insulin detemir

\section{Introduction}

This review examines the most recent MEDLINE search, and updates a previous review of insulin detemir compiled through June 30, 2006. ${ }^{1}$ This long-acting basal analog has unique properties including a more consistent pharmacodynamic profile, with less glycemic variability, a lower the risk of hypoglycemia and less weight gain. Insulin detemir appears to be the most suitable choice of basal insulin for clinicians who treat diabetes.

Normalization of glucose levels is the primary goal of managing patients with diabetes. The Diabetes Control and Complications Trial (DCCT), and the United Kingdom Prospective Diabetes Study (UKPDS), unequivocally demonstrated that tight metabolic control reduces the incidence, and also delays the development, of complications in patients with type 1 and type 2 diabetes, respectively. ${ }^{2-7}$ The DCCT/EDIC (Epidemiology of Diabetes Interventions and Complications) proved that intensive diabetes therapy had long-term beneficial effects by reducing the risk of cardiovascular disease in patients with type 1 diabetes after 17 years of treatment. ${ }^{8}$ Intensive therapy in the DCCT/EDIC trial was defined as basal insulin with pre-prandial short-acting insulin, or continuous insulin infusion. Intensive insulin therapy replicates normal physiology, utilizing a long-acting insulin analog, which provides a basal dose of insulin throughout the day, and adding short-acting insulin analog for mealtime dosing.

In type 1 diabetes, insulin is fundamental, utilizing a long-acting analog ( $\mathrm{qd} / \mathrm{bid})$, or a continuous, variable, subcutaneous infusion of short-acting analog insulin, 
supplemented with meal time short-acting analog bolus therapy. Insulin should be initiated early in the course of diabetes to attain optimal glucose control. Intensive management of type 2 diabetes, as in the Steno-2 Study, was associated with an average reduction of cardiovascular events by 7.8 years, as well as reduction in nephropathy, retinopathy and autonomic neuropathy by about half compared with a conventional multifactorial treatment. ${ }^{9}$

More recently, three large clinical studies, the Action to Control Cardiovascular Risk in Diabetes (ACCORD) trial, the Action in Diabetes and Vascular Disease (ADVANCE) trial, and the Veterans' Administration Diabetes Trial (VADT), invoked controversy. ${ }^{10}$ In ACCORD, all 10,251 patients were randomly assigned to receive comprehensive intensive therapy targeting a glycated hemoglobin level of less than $6.0 \%$ or to receive standard therapy targeting a level of $7.0 \%$ to $7.9 \%$. With the use of a double two-by-two factorial design, 4733 patients were randomly assigned to lower their blood pressure by receiving either intensive therapy (systolic bloodpressure target, $<120 \mathrm{mmHg}$ ) or standard therapy (systolic blood-pressure target, $<140 \mathrm{mmHg}$ ). In addition, 5518 patients were randomly assigned to receive either fenofibrate or placebo while maintaining good control of low-density lipoprotein cholesterol with simvastatin. The blood-pressure and lipid trials are continuing, and results for these remain masked. Of note, in ACCORD, all oral anti-diabetes agents (OADs), including multiple sulfonylureas, biguanides, alpha glucosidase reductase inhibitors and thiazolidinedione agents, were utilized to provide "intensive glycemic control," and it was this multi-drug treatment group that was terminated early, due to a higher rate of all cause mortality, although lower than predicted. This intensive group had significantly fewer nonfatal myocardial infarctions. The results of ADVANCE and the VADT conflict with ACCORD and beg the question for more uniformity of diabetes management, limiting the number of oral agents and utilizing insulin as basal, bolus or combinations of both when intensifying blood glucose levels.

The rate of hypoglycemic events was significantly more in all of these trials when diabetes management was intensified, irrespective of the use of insulin therapy. Future studies will need to examine insulin therapy in type 2 diabetes with limited use of OADs, quite possibly to metformin as the lone oral agent, since it has already demonstrated cardiovascular risk reduction in UKPDS. ${ }^{11}$ Potentially, a basal bolus arm should be considered in type 2 diabetes.

In the future, studies will examine cardiovascular risk reduction in type 1 and type 2 diabetes with a greater intent to define hypoglycemia as a major contributing cause of morbidity and death. Cardiovascular risk reduction trials will focus on glucose variability and targeting near-normal glycemic levels utilizing strategies and therapies which reduce postprandial glucose levels, and lower rates of hypoglycemia as well as technologies to better measure hypoglycemia, like continuous glucose sensing (CGM). ${ }^{12-15}$

Hypoglycemia and weight gain are beguiling issues for patients with type 1 and 2 diabetes, especially with intensive reduction of glucose levels. Theories abound, but there is evidence that basal insulin detemir is a predictable basal insulin with lower glycemic variability. These unique properties have been associated with less weight gain compared to NPH and glargine.

\section{Glycemic variability}

Insulin glargine is a modification of the amino acid sequence of human insulin, in that two arginine residues added to the $\mathrm{C}$ terminus of the B-chain shift the isoelectric point from pH 5.4 to 6.719. Insulin glargine is injected as a solute in an acidic formulation, forms a microprecipitate in the (neutral $\mathrm{pH}$ ) subcutaneous tissue, and has a prolonged duration of action due to its slow dissolution of the precipitate. Insulin glargine has a prolonged duration of action and is indicated for once-daily dosing. The precipitate depot represents a potential source of variability.

Insulin detemir's formulation is remarkably different from other basal insulins. The prolonged action of insulin detemir is accomplished by attaching a 14-carbon fatty acid chain (myristic acid) to the lysine residue at position B29 such that each monomer bears a myristic acid side chain. This side chain contributes to enhanced self-association of insulin detemir molecules in the subcutaneous depot and albumin binding in the subcutaneous depot, circulation and the interstitial tissue, resulting in a substantial prolongation of action. Insulin detemir is a clear neutral solution that is $98 \%$ albumin bound, with a duration of action of 24 hours, indicated for once- or twice-daily dosing, having an important buffering effect to limit pharmacodynamic variability.

Insulin glargine, on the other hand, is a modification of the amino acid sequence of human insulin, with two arginine residues added to the $\mathrm{C}$ terminus of the $\mathrm{B}$-chain shifting the isoelectric point from $\mathrm{pH} 5.4$ to 6.719 . Insulin glargine is injected as a solute in an acidic formulation and forms a microprecipitate in the (neutral $\mathrm{pH}$ ) subcutaneous tissue. The prolonged duration of action of this basal insulin is due to its slow dissolution of the precipitate which represents a potential source of its variability. 
Heise reviewed the pharmacodynamics data of both insulin detemir and glargine as derived with the glucose clamp technique. In this review, the common definition for duration of action (time from injection to plasma glucose $>8.3 \mathrm{mmol} / \mathrm{L}$ ) was applied, and study data were recalculated when necessary. Despite differences in methodological details, the results of most clamp studies were very consistent. Both analogs demonstrated a similar "gentle rise and fall in glucose-lowering action" over time. The duration of action with both analogs is dose dependent, ranging from of 0.35 to $0.8 \mathrm{U} / \mathrm{kg}$, and close to 24 hours in patients with type 1 diabetes. The dose range may be higher in type 2 diabetes. While both analogs seem to be very similar with regard to the mean shape of their pharmacodynamics profile and duration of action, detemir demonstrates less withinsubject variability in its metabolic effect. These findings in experimental glucose clamp studies are consistent with observations in clinical trials and support routine once daily use with either analog.

Danne et al compared the within-subject variability of insulin detemir and glargine in children and adolescents with type 1 diabetes in a recent, doubled blind, crossover trial. ${ }^{16}$ Thirty-two children and adolescents (19 girls and 13 boys; mean \pm SD: age $13 \pm 2.5$ years and type 1 diabetes duration $6.3 \pm 3.0$ years) with a hemoglobin $\mathrm{A} 1 \mathrm{c}\left(\mathrm{HbA}_{1 \mathrm{c}}\right)$ of $7.9 \% \pm 1.0 \%$, were randomized to a specific treatment sequence in which a dose of $0.4 \mathrm{U} / \mathrm{kg}$ of insulin detemir and insulin glargine was injected subcutaneously 24 hours apart at each of two dosing visits. Insulin detemir showed statistically significantly less within-subject variability compared with insulin glargine for children aged 8 to 12 years and adolescents 13 to 17 years. No safety concerns were raised during the trial. In a previous euglycemic clamp study involving patients with type 1 diabetes, by the same authors, the pharmacokinetic/pharmacodynamic properties of insulin detemir did not differ across all age groups including adults, ages 18 to 65 years. ${ }^{17}$ However, there appeared to be a greater sensitivity for patients over the age of 65 years, suggesting that slightly lower dosing may be as effective.

\section{Insulin determir: once or twice daily dosing}

In the just published ADAPT trial, Le Floch et al showed no difference in efficacy between once-daily and twice-daily dosing of insulin detemir in 520 patients with type 1 diabetes. Of interest is that patients who received detemir once daily had a lower total daily dose than the twice-daily group. ${ }^{18}$ In this 7-month trial, $\mathrm{HbA}_{1 \mathrm{c}}$ at 4 months was $8.1 \pm 0.9$ vs
$8.0 \% \pm 1.0 \%$ with qd and bid detemir, respectively, with an adjusted between-group difference of $0.12 \%$ (95\% CI $-0.01 ; 0.25 \%$ ), showing non-inferiority for qd dosing. Similar results were found in the per protocol population. Improvement in $\mathrm{HbA}_{1 \mathrm{c}}$ was similar in both groups $(-0.4 \pm 0.8$ vs $-0.5 \% \pm 0.8 \% ; p=0.09$, NS), but with differences in the 7-point glucose profile. Detemir doses were lower $(29 \pm 18$ vs $39 \pm 20 \mathrm{U} / \mathrm{d}, \mathrm{p}<0.001)$, but aspart doses higher $(34 \pm 17$ vs $26 \pm 14 \mathrm{IU} / \mathrm{d}, \mathrm{p}<0.001)$ with qd detemir. At 7 months, $\mathrm{HbA}_{1 \mathrm{c}}$ decreased slightly in patients switched from qd to bid $(8.2 \pm 0.8$ vs $8.0 \% \pm 0.8 \% ; p=0.34, \mathrm{NS})$ in association with increased total insulin doses $(\mathrm{p}<0.05)$ but $\mathrm{HbA}_{1 \mathrm{c}}$ increased in those switched from bid to qd (7.2 \pm 0.9 vs $7.6 \% \pm 0.8 \%$; $\mathrm{p}<0.05)$ in association with decreased doses $(\mathrm{p}<0.05)$.

\section{Efficacy: reduction of $\mathrm{HbA}_{\mathrm{lc}}$}

Insulin detemir has proven efficacy in type 1 and type 2 diabetes. Prior to 2006 several studies compared the efficacy of insulin detemir in both a once- and twice-daily dosing regimen with NPH insulin. ${ }^{19-27}$ All trials were multicenter, randomized, parallel-group and open-labeled. Most studies were conducted in patients with type 1 diabetes, and three large studies were conducted involving patients with type 2 diabetes.

The Predictable Results and Experience in Diabetes through Intensification and Control to Target: An International Variability Evaluation (PREDICTIVE) Study is a global, multi-center, open-label, observational study in patients with type 1 or type 2 diabetes who were transferred to insulin detemir for the management of their blood glucose. The information obtained from this trial reflects a "real world" experience and involves more than 30000 patients throughout the world. Of note, among the PREDICTIVE trials, the subgroup analysis of the German cohort of patients with type 2 diabetes $(n=6000),{ }^{28}$ and the Predictive 303 study, ${ }^{29}$ demonstrated superior $\mathrm{HbA}_{1 \mathrm{c}}$ reduction with insulin detemir, in patients with type 2 diabetes, previously treated with OADs, alone, or in combination with NPH or glargine.

Insulin detemir-treated patients achieved a $\mathrm{HbA}_{1 \mathrm{c}}$ reduction of $1.1 \% \pm 0.03 \%(\mathrm{p}<0.0001)$, achieving a mean $\mathrm{HbA}_{1 \mathrm{c}}$ at the end of study of $7.2 \% \pm 0.02 \%$. When insulin detemir was added to $\mathrm{OADs}, \mathrm{HbA}_{1 \mathrm{c}}$ decreased $1.29 \% \pm 0.3 \%$ ( $\mathrm{p}<0.0001$ from baseline), and those transitioning from $\mathrm{NPH}$ or glargine had an additional reduction in $\mathrm{HbA}_{\mathrm{lc}}$ of $0.6 \pm 0.9 \%$, and $0.59 \% \pm 0.6 \%(\mathrm{p}<0.0001)$, respectively. At the end of the study, $42.2 \%$ of patients achieved a $\mathrm{HbA}_{1 \mathrm{c}}$ of less than $7 \%$, compared to $10.8 \%$ at baseline $(p<0.0001)$. These studies demonstrate the efficacy of insulin detemir as 
the initial basal insulin for naïve patients on OADs, as well as more beneficial improvement in glycemic control when patients were switched from NPH or glargine.

The Predictive 303 study $(n=5604)$ evaluated the effectiveness of insulin detemir, using a simplified patient self-adjusted dosing algorithm (303 Algorithm group) compared with standard-of-care physician-driven adjustments (Standard-of-care group) in a predominantly primary care setting, over a period of 6 months. Insulin detemir was initiated once daily as add-on therapy to OADs, or as a replacement of pre-study basal insulin (NPH or glargine) in patients with type 2 diabetes. The self-adjusted 303 Algorithm group changed their insulin detemir dose every 3 days based on the mean of three "adjusted" fasting plasma glucose (aFPG) values (capillary blood glucose calibrated to equivalent plasma glucose values) using a simple algorithm: when the mean aFPG is $<80 \mathrm{mg} / \mathrm{dL}(4.4 \mathrm{mmol} / \mathrm{L})$, reduce dose by $3 \mathrm{U}$; when aFPG is between 80 and $110 \mathrm{mg} / \mathrm{dL}(4.4-6.1 \mathrm{mmol} / \mathrm{l})$, no change; when aFPG is $>110 \mathrm{mg} / \mathrm{dL}(1.1 \mathrm{mmol} / \mathrm{L})$, increase dose by $3 \mathrm{U}$. The dose of insulin detemir for patients in the standard-of-care group was adjusted by the investigator as they normally would do in their practice. Mean $\mathrm{HbA}_{1 \mathrm{c}}$ levels decreased from $8.5 \%$ at baseline to $7.9 \%$ at 26 weeks for the 303 Algorithm group and from $8.5 \%$ to $8.0 \%$ for the Standard-of-care group ( $\mathrm{p}=0.0106$ for difference in $\mathrm{HbA}_{1 \mathrm{c}}$ reduction between the two groups).

\section{Fasting glucose}

Fasting plasma glucose (FPG) levels were significantly reduced in the German cohort, with mean FPG levels reduced by $49.8 \pm 1 \mathrm{mg} / \mathrm{dL}(\mathrm{p}<0.0001)$.

Mean FPG values decreased from $175 \mathrm{mg} / \mathrm{dL}$ at baseline to $141 \mathrm{mg} / \mathrm{dL}$ for the 303 Algorithm group and decreased from $174 \mathrm{mg} / \mathrm{dL}$ to $152 \mathrm{mg} / \mathrm{dL}$ for the Standard-of-care group $(\mathrm{p}<0.0001$ difference in FPG reduction between the two groups).

\section{Lower rate of hypoglycemia}

In the German cohort, baseline total, daytime and nocturnal hypoglycemic events $(3.3,2.0$ and 1.3 events per patient year, respectively) decreased by $2.7,1.6$ and 1.2 , respectively ( $\mathrm{p}<0.0001$ ) during the study as did the percentage of patients experiencing these events $(7.2 \%, 5.5 \%$ and $3.7 \%$ at baseline compared to $2.0 \%, 1.6 \%$ and $0.5 \%$ at follow up). In Predictive 303, the overall rate of hypoglycemia (events/ patient/year) decreased significantly from baseline in both groups (from 9.05 to 6.44 for the 303 Algorithm group ( $p=0.0039$ ) and from 9.53 to 4.95 for the Standard-of-care group $\mathrm{p}<0.0001)$. Major hypoglycemic events were rare in both groups (0.26 events/patient/year for the 303 Algorithm group and 0.20 events/patient/year for the Standard-of-care group; $\mathrm{p}=0.2395$ ).

\section{Less weight gain}

In Predictive, rather than expected weight gain, with improved glycemic control, overall reduction in glucose levels was accompanied by a $0.9 \pm 0.1 \mathrm{~kg}$ weight reduction $(\mathrm{p}<0.0001)$. Specifically, when patients were transitioned from the three groups: OADs alone; OADs with $\mathrm{NPH}$, or insulin glargine, weight reductions of $0.9 \pm 0.1 \mathrm{~kg}(\mathrm{p}<0.0001), 0.9 \pm 0.3 \mathrm{~kg}$ $(\mathrm{p}=0.00099)$ and $0.8 \pm 0.2 \mathrm{~kg}(\mathrm{p}<0.0001)$ were noted. Strikingly, when glycemic control improved, the rate of hypoglycemia and weight loss was significantly lower than expectations from previous studies with other basal insulins. In the Predictive 303 study, mean body weight remained the same at 26 weeks in both groups (change from baseline 0.1 and $-0.2 \mathrm{~kg}$ for the 303 Algorithm group and the Standard-ofcare groups respectively). At 26 weeks, $91 \%$ of the patients in the 303 Algorithm group and $85 \%$ of the patients in the Standard-of-care group remained on once-daily insulin detemir administration.

Interestingly, in another 52-week trial, when insulin detemir was titrated based on pre-breakfast and pre-dinner plasma glucose target of $108 \mathrm{mg} / \mathrm{dL}$ or less, the patients who were adjusted to twice-daily dosing had less overall weight loss compared to insulin glargine. If glargine had been titrated in the same manner to twice-daily dosing based on the same titration as detemir, glargine would have been dosed twice daily as often as detemir and possibly would have been higher. Nevertheless, insulin detemir had superior $\mathrm{HbA}_{1 \mathrm{c}}$ reduction, less hypoglycemia, and weight gain was lower, $3.0 \mathrm{~kg}$ for detemir compared to $3.9 \mathrm{~kg}$ for the glargine group. ${ }^{30}$

The most recent Predictive BMI study was the first study to examine the effect of once-daily detemir with weight as the primary endpoint in a large population of overweight type 2 diabetes patients. Use of once-daily detemir for intensification of insulin therapy resulted in less weight gain, less hypoglycemia and equivalent glycemic control compared with NPH. ${ }^{31}$ At 26 weeks, weight had increased significantly less with detemir $(0.4 \mathrm{~kg})$ than with NPH $(1.9 \mathrm{~kg}$; difference $1.5 \mathrm{~kg}, \mathrm{p}<0.0001)$. The BMI increase was also less with detemir than with NPH (difference $0.6 \mathrm{~kg} / \mathrm{m}^{2}, \mathrm{p}<0.0001$ ). The $\mathrm{HbA}_{1 \mathrm{c}}$ decrease was not significantly different, from $8.9 \%$ to $7.8 \%$ with detemir and from $8.8 \%$ to $7.8 \%$ with NPH. The incidence of hypoglycemia was lower with deemed 
and relative risks 0.62 (all events) and 0.43 (nocturnal) ( $\mathrm{p}<0.0001$ for both).

\section{Conclusion}

Insulin detemir is the most suitable basal analog insulin, with lower within-patient variability, and consistent reductions in FPG levels. The pharmocokinetic/pharmacodynamic properties of insulin detemir have demonstrated lower rates of hypoglycemia and weight gain, making it an ideal choice to manage patients with diabetes.

Trials intended to reduce cardiovascular risk should continue to explore the benefits of intensification and normalization of glucose levels. The management of these patients with type 2 diabetes should be simplified with metformin alone and insulin detemir with the intention of focusing on hypoglycemic events. Another consideration in the future will be to analyze the total daily insulin dose and, specifically, to limit the total basal insulin dose to less than $50 \%$ of total, and ideally less than $0.5 \mathrm{U} / \mathrm{kg}$, since this has been associated with superior glycemic control, lower fasting glucose levels and less weight gain. ${ }^{32}$ Insulin detemir should be given strong consideration as basal insulin diabetes management. Recent information is compelling to suggest this basal analog insulin as the agent of choice in type 2 diabetes.

\section{Disclosures}

The author is a clinical investigator, a paid consultant, and owns common stock (individual investment) in Novo Nordisk, Inc. He is also a paid consultant and clinical investigator for Lilly, Sanofi-Aventis, Pfizer, Merck, Medtronic, Inc., and Johnson and Johnson. The author is also a paid consultant, clinical investigator and owns common stock (individual investment) in Amylin Pharmaceuticals.

\section{References}

1. Peterson GE. Intermediate and long-acting insulins: a review of $\mathrm{NPH}$ insulin, insulin glargine and insulin detemir. Curr Med Res Opin. 2006;22:2613-2619.

2. The Diabetes Control and Complications Trial Research Group. The absence of a glycemic threshold for the development of long-term complications. Diabetes. 1996;45:1289-1298.

3. Reichard $\mathrm{O}$, et al. The effect of long-term intensified insulin treatment of microvascular complications of diabetes mellitus. $N$ Engl J Med. 1993;329:304-309.

4. Wang PH, et al. Meta-analysis of effects of intensive blood-glucose control on late complications of type I diabetes. Lancet. 1993;341:1306-1309.

5. The Diabetes Control and Complications Trial Research Group. Hypoglycemia in the Diabetes Control and Complications Trial. Diabetes. 1997;46:271-286.

6. Nathan DM, et al. Intensive diabetes treatment and cardiovascular disease in patients with type 1 diabetes. $N$ Engl J Med. 2005;353(25): 2643-2653.
7. Stratton IM, et al. Association with glycaemia with macrovascular and microvascular complications of Type 2 diabetes (UKPDS 35): prospective observational study. BMJ. 2000;321:405-412.

8. Intensive diabetes treatment and cardiovascular disease in patients with type 1 diabetes. The Diabetes Control and Complications Trial/ Epidemiology of Diabetes Interventions and Complications (DCCT/ EDIC) Study Research Group. N Engl J Med. 2005;353:2643-2653.

9. Gæde P. Intensive integrated therapy of type 2 diabetes: implications for long-term prognosis. Diabetes. 2004;53:S39-S47.

10. Bloomgarden ZT. Glycemic control in diabetes: a tale of three studies. Diabetes Care. 2008;31:1913-1919.

11. Wright A. Sulfonylurea inadequacy: efficacy of addition of insulin over 6 years in patients with type 2 diabetes in the UK. Prospective Diabetes Study (UKPDS 57). Diabetes Care. 2002;25:330-336.

12. Dluhy RG. Intensive Glycemic Control in the ACCORD and ADVANCE Trials. N Engl J Med. 2008;358:2630-2633.

13. Hirsch IB. Should minimal blood glucose variability become the gold standard of glycemic control? J Diabetes Complicat. 2005;19: 178-181.

14. Unger J. Reducing oxidative stress in patients with type 2 diabetes mellitus: A primary care call to action. Insulin. 2008;3(3):176-184.

15. Rendell MS. Targeting postprandial hyperglycemia. Metabolism. 2006;55:1263-1281.

16. Insulin detemir is characterized by a more reproducible pharmacokinetic profile than insulin glargine in children and adolescents with type 1 diabetes: results from a randomized, double-blind, controlled trial. Pediatr Diabetes. 2008;9:382-387.

17. Danne T. Insulin detemir is characterized by a consistent pharmacokinetic profile across age-groups in children, adolescents, and adults with type1 diabetes. Diabetes Care. 2003;26:3087-3092.

18. Le Floch JP, et al. A comparison of once- versus twice-daily administration of insulin detemir, used with mealtime insulin aspart, in basal-bolus therapy for type 1 diabetes: assessment of detemir administration in a progressive treat-to-target trial (ADAPT). Diabetes Care. 2009;32:32-37.

19. Home $\mathrm{P}$, et al. Insulin detemir offers improved glycemic control compared with NPH insulin in people with type I diabetes: a randomized clinical trial. Diabetes Care. 2004;27:1081-1087.

20. Russell-Jones D, et al. Effects of QD insulin detemir or neutral protamine hagedorn on blood glucose control in patients with type I diabetes mellitus using a basal- bolus regimen. Clin Ther. 2004;26:724-736.

21. Robertson $\mathrm{K}$, et al. Benefits of insulin detemir over NPH insulin in children and adolescents with type 1 diabetes: lower and more predictable fasting plasma glucose and lower risk of nocturnal hypoglycemia. Diabetes. 2004;53(Suppl 2):A144.

22. Hermansen $\mathrm{K}$, et al. Insulin analogues (insulin detemir and insulin aspart) versus traditional human insulins (NPH insulin and regular human insulin) in basal-bolus therapy for patients with Type 1 diabetes. Diabetologia. 2004;47:622-629.

23. Kolendorf $\mathrm{K}$, et al. Insulin detemir is associated with lower risk of hypoglycemia than NPH insulin in people with type 1 diabetes. Diabetes. 2004;53 Suppl 1:A130.

24. Pieber TR. Comparison of three multiple injection regimens for Type 1 diabetes: morning plus dinner or bedtime administration of insulin detemir versus morning plus bedtime NPH insulin. Diabetic Med. 2005;22:850-857.

25. Haak $\mathrm{T}$, et al. Lower within-subject variability of fasting blood glucose and reduced weight gain with insulin detemir compared to NPH insulin in patients with type 2 diabetes. Diabetes Obes Metab. 2005;7:56-64.

26. Raslova $\mathrm{K}$, et al. Insulin detemir and insulin aspart: a promising basal-bolus regimen for Type 2 diabetes. Diabetes Res Clin Pract. 2004;66:193-201.

27. Hermansen K, et al. A 26-week, randomized, parallel, treat-to-target trial comparing insulin detemir with NPH insulin as add-on therapy to oral glucose- lowering drugs in insulin-naïve people with Type 2 diabetes. Diabetes Care. 2006;29:1269-1274. 
28. Meneghini LF, Insulin detemir improves glycaemic control with less hypoglycaemia and no weight gain in patients with type 2 diabetes who were insulin naive or treated with NPH or insulin glargine: clinical practice experience from a German subgroup of the PREDICTIVE study. Diabetes Obes Metab. 2007;9:418-427.

29. Meneghini L. Efficacy and safety of insulin detemir in a large cohort of patients with type 2 diabetes suing a simplified self-adjusted dosing guideline - results of the PREDICTIVE 303 study. Program and abstracts of the 67th Scientific Sessions of the American Diabetes Association; June 22-26, 2007; Chicago, Illinois. Abstract 197-OR.
30. Rosenstock J. A randomised, 52-week, treat-to-target trial comparing insulin detemir with insulin glargine when added to glucose-lowering drugs in insulin-naïve people with Type 2 diabetes. Diabetologia. 2008;51:408-416.

31. Fajardo Montañana C, Less weight gain and hypoglycaemia with once-daily insulin detemir than NPH insulin in intensification of insulin therapy in overweight Type 2 diabetes patients: the PREDICTIVE BMI clinical trial. Diabet Med. 2008;25(8):916-923.

32. Peterson GE. Insulin detemir in type 1 and type 2 diabetes [abstract]. Ehrlich II World Congress, Nurenberg, Germany, October 2008.

\section{Publish your work in this journal}

Diabetes, Metabolic Syndrome and Obesity: Targets and Therapy is an international, peer-reviewed open-access journal committed to the rapid publication of the latest laboratory and clinical findings in the fields of diabetes, metabolic syndrome and obesity research. Original research, review, case reports, hypothesis formation, expert opinion and commentaries are all considered for publication. The manuscript management system is completely online and includes a very quick and fair peer-review system, which is all easy to use. Visit http://www.dovepress.com/testimonials.php to read real quotes from published authors.

Submit your manuscript here: http://www.dovepress.com/diabetes-metabolic-syndrome-and-obesity-targets-and-therapy-journal 